\title{
A SYSTEMATIC APPROACH TO THE DILEMMA BETWEEN FLOOD VULNERABILITY AND RESILIENCE - REVIEW AND CONCEPTS
}

\author{
Hoang Cong Tri ${ }^{1, ~ *}$, Luc Hens ${ }^{2}$, Pham Minh Thien Phuoc ${ }^{3}$, \\ Nguyen Thanh Hung ${ }^{1}$, Tran Ha Phuong ${ }^{4}$ \\ ${ }^{1}$ Representative office VAST, 01 Mac Dinh Chi street, District 1, Ho Chi Minh City, Vietnam \\ ${ }^{2}$ Flemish Institute for Technological Research (VITO), Boeretang 200, $2400 \mathrm{Mol}$, Belgium \\ ${ }^{3}$ Department of East Asian Economics, Ruhr Bochum Universität, \\ Universitätsstraße 150, 44801 Bochum, Germany \\ ${ }^{4}$ Ho Chi Minh City Institute of Resources Geography, VAST, \\ 01 Mac Dinh Chi Street, District 1, Ho Chi Minh City, Vietnam \\ *Email: cong.hoang@uqconnect.edu.au
}

Received: 03 February 2017; Accepted for publication: 28 June 2017

\begin{abstract}
The nature of "vulnerability" is that it not only exists when elements at risk are exposed to flood, but also hides in interactions between environmental, social and economic factors before the flood incident. While ecological resilience reflects the dynamic characteristics of resources, ecological vulnerability systematically describing aspects of stress was less researched. This paper develops a concept, modeling dynamic interactions between stress and resources taking into account of context, space, time, and stakeholder involvements, to provide direct causes and solutions for flood risk management. The paper reviews three major schools of thought concerning (i) vulnerability and resilience are two sides of the same coin, (ii) resilience is a part of vulnerability, and (iii) they are two separated concepts with some overlaps. Limitations of the schools of thought were assessed based on four main criteria: (i) vulnerability and resilience must reflect all social, economic and environmental aspects, (ii) they exist regardless of hazards, (iii) they are processes than outcomes, and (iv) they entail multiple objectives. Inspired by the flipping coin and separated concepts, a new framework is developed. It acknowledges from outstanding points of the two that vulnerability and resilience are normalized as stress and resources of the same coin. They can generate positive and/or negative outcomes. Therefore, their relationships are complex because resources, defined by stakeholders, may prevent system changes and consequently amplify stress. Depending on the ratio between stress and resources, a system can be characterized as a 'resistant', or a 'creative' regime. If incremental disturbances exceed the recovery threshold as defined by the available data and the stakeholders, the system might change regime. Decision makers can take advantage of this framework to increase the resilience of a community and anticipate adverse effects for incoming floods.
\end{abstract}

Keywords: vulnerability, resilience, resources, stress, regime shift. 


\section{INTRODUCTION}

Vulnerability and resilience are two crucial components of flood risk assessment [1]. Definitions of vulnerability and resilience vary, but in general vulnerability refers to potential disturbances and resilience relies on resources that protect system functions [2]. Both concepts are abstract but show specific (sets of) characteristics [3]. Perceptions about vulnerability and resilience can confuse because they integrate social, economic and environmental aspects, and more interestingly, they can both create positive and/or negative outcomes [4]. Consequently, different approaches on vulnerability and resilience lead to different adaptation strategies. Some studies consider them as two sides of a same coin [1, 5, 6, 7], some use resilience as the system's capacity to reduce potential vulnerability [8-11], while others recognize they are two separated concepts with overlaps [4, 12 - 16]. Although the three schools of thought vulnerability and resilience as dynamic processes across contexts, scale, time, and stakeholder involvement, they inadequately allow measuring vulnerability in non-flood (normal) conditions. This results in an incomplete comparison between vulnerability and resilience. Resilience often reflects the complete characterization of coping and adaptation capacities of a system [11]. Traditionally vulnerability only focuses on quantifying stress at flood incidents [3]. Communities are, however, heterogeneous entities where human and natural systems are interconnected [1]. Communities are "unbounded" systems rather than "closed" entities (such as administrative units) [13]. Addressing multiple aspects of vulnerability assessment is essential because of the variety of involved stakeholders or individuals, their agendas and socio-economic backgrounds in a community. This heterogeneity results in vulnerability which is not only present when the system is exposed to a flood. Therefore, calculating vulnerability on the basis of incidents at the time a flood happens is insufficient. Beroya-Eitner [17] suggests that "ecological vulnerability" should describe all types of stress caused by human-nature interactions during both floods and prior to the floods. Systematically examining the interactions between ecological vulnerability and resilience, this paper provides answers to questions on how realizing their separation. This allows describing the momentum of system changes prior to and during a flood. The interactions generate multiple flipping-coin effects over a geospatial space.

\section{VULNERABILITY}

Vulnerability is a multifaceted concept of which the content varies across disciplines and organizations. It often reflects a series of environmental and socio-economic indicators, which are dynamic due to changes in natural systems or to human interactions [5, 18 - 21]. The current literature does not provide a standard for vulnerability assessment. Nevertheless quite a complete conceptual framework has been developed covering all essential aspects of vulnerability that are useful to be applied in flood risk management [22].

A variety of definitions of "vulnerability" exists. UNISDR [23] for example, refers to vulnerability as the susceptibility of social, economic and environmental aspects [23]. Schanze [20] sees vulnerability as the intrinsic characteristics of elements, which are prone to harm. He points to three basic sustainability dimensions of flood vulnerability: social (including cultural), economic and ecological vulnerability. Dewan [24] lists three major premises of vulnerability: (i) Vulnerability as an outcome of the hazard and characterized by exposure, sensitivity, and potential consequences. This approach is based on the risk and hazard paradigm of humannature interactions. (ii) Social, environmental and cultural aspects of communities or individuals to determine why a particular community is vulnerable and why harmful effects of hazards on a 
community are unevenly distributed. (iii) The third presumption uses "sustainable development" and emphasizes self-healing of socio-ecological systems [5]. Bizimana and Schilling [25] dissect flood vulnerability in its physical, social and economic dimensions and their (composite) interactions. Physical vulnerability focuses on the fragility or weakness of the exposed objects to the flood hazards. Social vulnerability is associated with the lack of skills and resources to prevent, cope with and/or recover from the hazards. Economic vulnerability relates to financial values and primarily refers to low-income citizens who often live in floodplains and lack the support of the local governments [26]. Therefore, it is important determining how well communities are prepared to adapt to or to cope with floods during all stages of the management cycle. Composite vulnerability is a concept of increasing importance in the current scientific research. It refers to physical, social, economic and environmental factors. Composite vulnerability shifts the focus from physical and social effects of floods to a wider understanding of vulnerability as a process, and a dynamic product of socio-economic and environmental convergences, which vary over space and time [27]. In other words, composite vulnerability refers explicitly to the connections between harmful effects and the coping capacity based on the socio-economic, ecological and demographic background of the exposed communities and/or individuals [28].

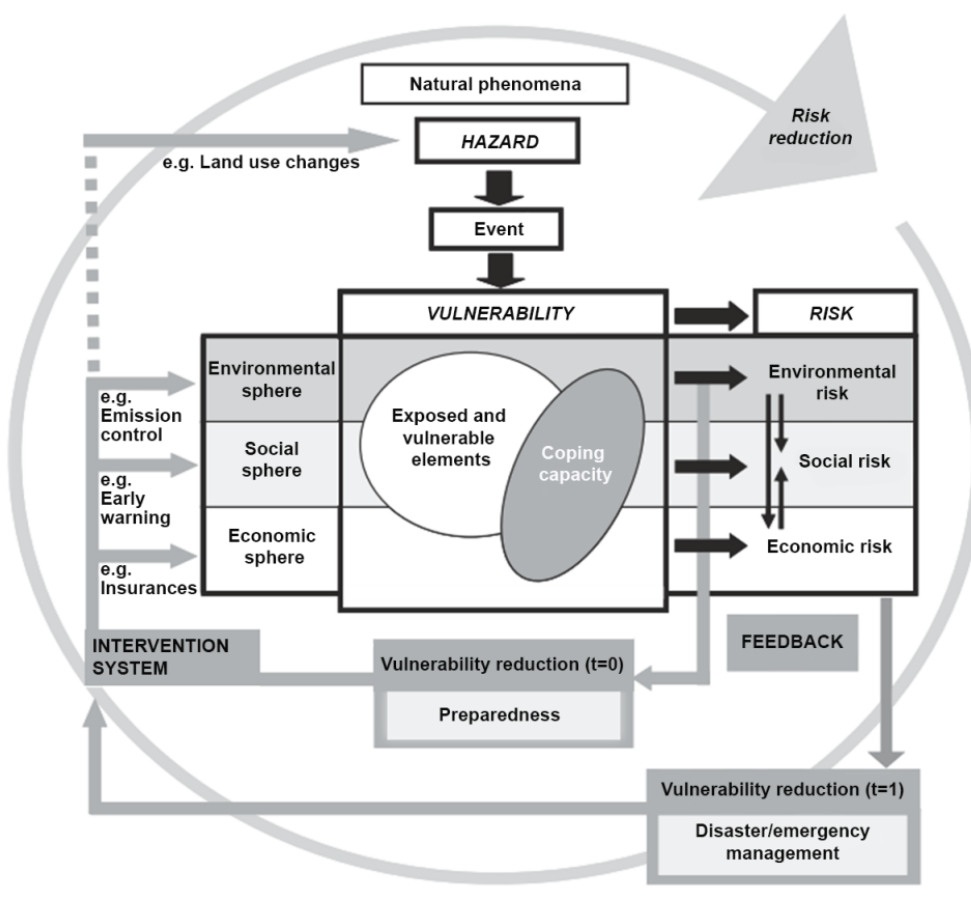

Figure 1. The BBC conceptual framework was designed as a monitoring system for environmental, social, and economic spheres. When a hazard occurs, the vulnerability in environmental, social, and economic aspects of the exposed elements will be calculated. A feedback loop returns information about disaster management to intervention system for future hazards [29 - 31]. Limitations of the framework:

(a) no information on scaling effects, (b) vulnerability is only calculated based on the incidents, and

(c) management phases may overlap in practical applications.

An in depth review of different vulnerability concepts refers to the BBC framework which was established by Bogardi and Birkmann [29], Cardona [30 - 31] (Figure 1). The model takes into account social, economic and environmental dimensions. The BBC framework analyzes 
vulnerability in a context of capacity and pro-activity of intervention measures [32]. These preinterventions are particularly crucial in flood risk management, as they significantly influence the cost of flood responses and recovery. Three major drawbacks of the BBC concept are: (i) It does not scale effects as environmental, social, and economic components. (ii) Vulnerability is calculated just as a hazard incident; this does not cover adequately the complete human-nature interactions [17]. (iii) The flood management cycle is an obsolete concept [33]. The purpose of a management cycle is among others to allocate appropriate responsibilities of those who are involved. In a spiral development, some complex events need to coincide for example, a single large-scale disaster may relate to a number of small and medium disasters. When a disaster occurs, many participatory sectors will find themselves at different stages of the cycle at the same time [24].

\section{RESILIENCE}

Both vulnerability and resilience are central concepts providing frameworks for mitigating adverse consequences of hazards. Just as vulnerability, resilience entails social, environmental, and economic components, which change over space and time. However, resilience refers to resources and systems responding to disturbances. Resilience is the capacity of a system to absorb and cope with disturbances in the short-term and to reorganize and improve this capacity during a long-term period without losing the system's services [3]. Resilience of a community to flood is a process in which capacity building or enhancement responding to different magnitudes of the disturbance varies across flood stages [21].

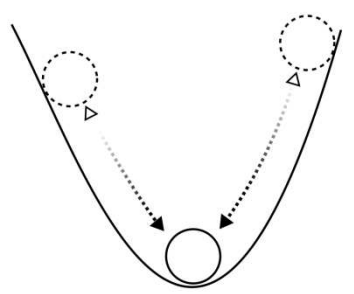

a) engineering resilience

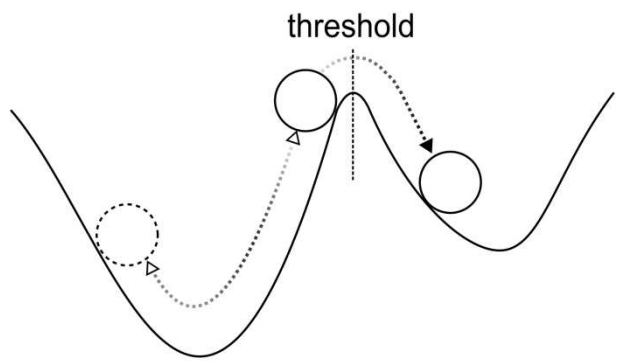

b) ecological resilience

Figure 2. Comparison between engineering and ecological resilience. a) Engineering resilience refers to the movement of a system around its stable equilibrium. b) Ecological resilience refers to multiple equilibria. The balance of a system depends on the challenges of disturbances and resources.

The system can leave the existing regime and move to a new equilibrium [35].

Overall, there are two major approaches to resilience: an engineering and an ecological one [34]. Ecological resilience reflects the dynamics of the system (Figure 2b). Engineering resilience (Figure 2a) refers to the ability of a system returning to a stable equilibrium after a shock. It focuses on protecting the functional stability of engineering systems. Engineering resilience assumes only one regime and considers whether the system can resist at the very bottom of the regime [34]. The speed with which the system returns to the equilibrium depends on four aspects: the physical strength to tolerate disturbances without losing the system's functions, the ability to quantify the threats and allocate resources, the ability to substitute the components of the system, and the internal coping ranges by which the system can be restored timely [35]. Resistance of engineering systems is crucial in explaining why resilience may be 
positive (e.g. absorbing shocks) or negative (e.g. resist system's changes). In practice, the approach of engineering resilience is problematic because the interactions between disturbances and resources will re-configure the current system to establish a new, more optimal reference state eventually far from a steady equilibrium [16].

Table 1. Comparison between engineering and ecological resilience.

Engineering resilience Ecological resilience References

\begin{tabular}{|c|c|c|c|}
\hline $\begin{array}{l}\text { Theoretic } \\
\text { construct }\end{array}$ & $\begin{array}{l}\text { Resilience }=\text { resistance }+ \\
\text { recovery }\end{array}$ & $\begin{array}{l}\text { Resilience }=\text { tolerance }+ \\
\text { reorganization }\end{array}$ & [35] \\
\hline $\begin{array}{l}\text { Types of } \\
\text { equilibrium }\end{array}$ & $\begin{array}{l}\text { One equilibrium (one } \\
\text { regime) }\end{array}$ & $\begin{array}{l}\text { Multiple equilibria } \\
\text { (multiple regimes) }\end{array}$ & {$[16,35]$} \\
\hline Pre-conditions & Stability near equilibrium & Far from equilibrium & {$[6,16]$} \\
\hline Focus & $\begin{array}{l}\text { - Speed to return to the } \\
\text { equilibrium } \\
\text { - Protect the existing } \\
\text { configurations of the } \\
\text { system } \\
\text { - Detect the } \\
\text { engineering } \\
\text { equilibrium }\end{array}$ & $\begin{array}{l}\text { - System evolvement } \\
\text { through multiple } \\
\text { equilibria } \\
\text { - Explore modifications } \\
\text { of the system } \\
\text { - Detect regimes }\end{array}$ & {$[16,35,36]$} \\
\hline Roles of shocks & Threats & Learning opportunities & {$[35]$} \\
\hline Properties & $\begin{array}{l}\text { Robustness, redundancy, } \\
\text { resourcefulness, rapidity }\end{array}$ & $\begin{array}{l}\text { Self-organization, } \\
\text { adaptive capacity } \\
\text { redundancy }\end{array}$ & {$[16,35]$} \\
\hline $\begin{array}{l}\text { Measurement } \\
\text { scale }\end{array}$ & Quantitative & Mainly qualitative & [6] \\
\hline Variables & Functional variables & $\begin{array}{l}\text { Slowly-changing } \\
\text { variables }\end{array}$ & {$[6]$} \\
\hline
\end{tabular}

In contrast to engineering resilience, ecological resilience explores the tolerance and reorganization of the system through multiple equilibria (Table 1). Ecological resilience relates to (i) the capacity to absorb disturbances, (ii) the preparedness for other flood events, and (iii) the integration of multiple resources [35]. Self-organization, refers to the coping capacity in which the internal ability of the system allows a quick re-organization and resolving disruptions without external resources. A second characteristic of ecological resilience concerns the adaptive capacity contributing to resilience in the long-term, as it indicates the ability to learn from each flood and to adjust the system to internal and external changes. The last one, redundancy of ecological resilience, refers to the diversity of opportunities from various disciplines and institutes to enhance long-term adaptation [37].

\section{THE VAGUE BORDERS BETWEEN VULNERABILITY AND RESILIENCE}

Three main schools of thought exist when it comes to distinctions between vulnerability and resilience in a context of risk management: (i) they are two sides of the same coin, (ii) resilience 
is part of vulnerability, and (iii) both are distinct concepts with some overlaps (Table 2). The first one focuses on risks and benefits of management, while the second characterizes the dynamics of vulnerability when a system is exposed to flood. The third one takes into account the heterogeneity of stakeholders' strategies [13,16]. Regardless of the attempts to define and measure vulnerability and resilience, the analyses about how vulnerability interacts with ecological resilience are still vague and remain challenging.

Table 2. Comparison of vulnerability and resilience.

\begin{tabular}{|c|c|c|}
\hline $\begin{array}{l}\text { Two sides of the same } \\
\text { coin }\end{array}$ & $\begin{array}{c}\text { Resilience as a part of } \\
\text { vulnerability }\end{array}$ & $\begin{array}{c}\text { Separated concepts with some } \\
\text { overlaps }\end{array}$ \\
\hline $\begin{array}{l}\text { - Vulnerability as stress } \\
\text { Stress occurs when } \\
\text { resources are } \\
\text { threatened, lost or } \\
\text { individuals fail to get } \\
\text { resources } \\
\text { Vulnerability is } \\
\text { associated with a } \\
\text { 'negative' notion, } \\
\text { while resilience is } \\
\text { associated with a } \\
\text { 'positive' notion } \\
\text { No community is } \\
\text { always vulnerable or } \\
\text { resilient }\end{array}$ & $\begin{array}{l}\text { - Resilience and } \\
\text { vulnerability } \\
\text { complement each other } \\
\text { in sustainability science } \\
\text { - } \text { Resilience focuses on } \\
\text { the capacity of the } \\
\text { system to return to the } \\
\text { original state after a } \\
\text { shock } \\
\text { - Vulnerability = } \\
\text { exposure + } \\
\text { susceptibility + adaptive } \\
\text { capacity } \\
\text { Focus on detecting the } \\
\text { system's capacity ranges } \\
\text { to reduce potential } \\
\text { vulnerability }\end{array}$ & $\begin{array}{l}\text { Both are processes driven by } \\
\text { interactions between human } \\
\text { systems, environmental } \\
\text { systems and the built } \\
\text { environment } \\
\text { - Vulnerability refers to } \\
\text { weakness and fragility while } \\
\text { resilience involves } \\
\text { effectiveness of adaptations } \\
\text { Resilience can be either } \\
\text { positive (e.g. absorb shocks) or } \\
\text { negative (e.g. prevent system } \\
\text { changes) } \\
\text { Types of governance } \\
\text { (utilitarian, libertarian, } \\
\text { communitarian, etc.) amplify } \\
\text { various contents of resilience }\end{array}$ \\
\hline$[1,5-7,37]$ & {$[8,9,10,11,22,38]$} & {$[2,4,12-16,39]$} \\
\hline
\end{tabular}

\subsection{Flipping coin}

The first school of thought uses system theory to explain the contradiction between vulnerability and resilience. As long as both concepts rely on the same elements, they are two sides of a flipping coin $[1,5,6,7,37]$. Both concepts are considered as opposite because one is a stress or harm for the system, while the other protects the system's functions [7]. According to Wilson [1], they are opposite ends of a spectrum; therefore, weak resilience results in high vulnerability. This contradiction applies when vulnerability and resilience are internal states of a system which exists independently of the external hazards [40]. In the case of flood, vulnerability depends also on external factors as exposure and sensitivity, which change the system's structure and its components [2]. Consequently, pre-defined vulnerability and resilience prior to the flood are no longer seen as opposite during the calamity.

Conventional flood risk management often focuses on calculating the vulnerability at the time the hazard occurs, ignoring that vulnerability is a multiple stress determined by social, economic, and environmental conditions before, during and after the flood. For example, the 
effects of the 2005 flood in New Orleans, US persisted during months after the water receded [41]. Stress of floods on a local community is more intense if the pre-flood vulnerability and the flood exposure are combined [7]. Vulnerability and resilience are not always correctly described by 'negative' and 'positive' impacts, respectively because e.g. resilience may be a negative factor if it obstructs system changes [39]. The same applies to vulnerability. For example, periodic floods provide nutrients to agricultural fields [35]. The concepts 'bad vulnerability' and 'good resilience' depend on time, scale and context. They reflect aspects of the dynamic interactions between vulnerability and resilience in a community. A community is not a homogeneous entity because its individuals and stakeholders use different resources and strategies to cope with stress [1]. Some stakeholder's resources might be contradicting with those of others; therefore, resilience for a part of a community may turn out negatively for another group [39]. The multiple resources a community uses explain why the relations between vulnerability and resilience are not linear.

\subsection{Resilience as part of vulnerability}

The second school of thought focuses on resilience as an element to reduce vulnerability. The dynamic process of vulnerability across scale and time is analyzed, while admitting that exposure and capacity are two components of vulnerability. Therefore, when there is no flood and thus no exposure, vulnerability can be measured just by resilience. Consequently, this approach does not acknowledge that vulnerability and resilience exist in any system [1].

Füssel [8] examines the cross-scale vulnerable of a system independent of particular research traditions, as those of socio-economic systems [42] or coupled human-environment systems [10]. It is noteworthy that hazards are not always defined as the external causes of adverse effects on the system, but sometimes as internal causes. For example, land use planning may result in an unsustainable development of a community [8]. Therefore, environmental, social and economic attributes of a focal system should also be examined at coarser and finer levels. This is the main reason to classify system properties in multi spatio-temporal scales. Even if the method acknowledges the existence of vulnerability in multiple disciplines and spatiotemporal scales, the approach is hampered by delineating internal and external factors, which cause confusion. For example, national economic indicators are internal for a national assessment, but external to a city. Efforts to enhance the capacity of the community dealing with multiple stress factors are always a central concern. Jacobs et al. [38], Smit and Wandel [9], and Yohe and Tol [11] point to the variability of resources and the ability of a system to use them effectively. Lastly, both vulnerability and resilience are non-linear processes, cross-scale alterations, and subject to multiple changes by stakeholders [10]. Overall, the second school of thought puts a focus on risks deteriorating the functions of a system, rather than describing the dynamics between vulnerability and ecological resilience within the interactions of human and environmental systems, and the built environment [12].

\subsection{Separated concepts with overlaps}

Even when vulnerability refers to the fragility of a system for shocks, and resilience is about the ability to absorb shocks and to protect the functions of a system, they are not necessarily two sides of a coin. This is because they are characterized by indicators reflecting the objectives of the stakeholders. In a specific context, time, and scale, resilience may produce negative outcomes [39]. If the flipping-coin concept defines indicators based on outcomes rather than on processes, they cause confusion between vulnerability and resilience. For instance, a 
static indicator as income per capita, does not represent functional processes of vulnerability or resilience over time. A better indicator is the proportion of the employed labor force [43].

Stakeholder involvement is important to reduce conflicts in flood management strategies [42-43]. A set of characteristics allowing to compare vulnerability and resilience across scale and time, can only be applied if the stakeholders agree. Priority indicators can be defined, which can be ranked according to their importance, and possible overlaps can be avoided. Vulnerability might be used for short-term impacts of specific risks, while resilience covers the broad spectrum of impacts and adaptations [3]. These differences mean resilience works well in a dynamic environment and can contribute to better decisions under uncertainty. The literature shows a consistent agreement when it comes to recognizing that both concepts refer to dynamic processes relying on multiple contexts, time, scale, and stakeholder involvement $[2,5,8,44]$. Therefore, some indicators include components of both vulnerability and resilience [13,16]. For instance, a household income can contribute to resilience and/or to vulnerability. High-income families might invest in the physical quality of their houses or purchase an insurance to increase their social resilience while decreasing their vulnerability to flood. At the same time low-income groups might neglect these instruments. Consequently, their socio-economic status continues showing a high vulnerability and/or a low resilience. Even when one understands the differences between both concepts, their overlaps are hard to detect. They depend on which adaptation strategies generate negative effects. For instance, a dyke might increase resilience to flood of a community in stable situations. But, when floods happen, the dyke might break. This consequence might combine with other unpredictable weather conditions to intensify the vulnerability of the community [35]. Adapting the resources to the objectives of the stakeholders modifies the capacity of the system to cope with disturbances.

Also governance options and policies affect the use of resources [15] . For instance, liberals tend to consider that individuals have their own responsibility improving their adaptation capacity. Socialists on the contrary, prefer public rather than private strategies towards adaptation, because this approach favors equity. Therefore, adaptation strategies of a particular nation cannot just be transferred to another country. Within each community, a variety of stakeholders is involved in flood risk management: their individual strategies can be redundant or even contradictory [1].

In conclusion, resilience shows a wide range of aspects which partially overlap with vulnerability. Therefore, defining appropriate indicators for vulnerability and resilience is a daunting task with challenging aspects: Which indicators of vulnerability overlap with the resilience ones? Is there a common set of vulnerability and resilience indicators that can be used to assess and compare community resilience to flood across space and time? Overall, this third school of thought focuses on the heterogeneity of selecting vulnerability and resilience indicators driven by the objectives of the stakeholders. The dynamic interactions between vulnerability and resilience are still vague and rely on how well one succeeds in specifying the indicators.

\section{CONCEPTUAL FRAMEWORK INTEGRATING THE DYNAMIC INTERACTIONS BETWEEN ECOLOGICAL VULNERABILITY AND RESILIENCE}

The lack of a clear vision on ecological vulnerability results in vague comparisons between the three approaches. Ecological vulnerability emphasizes the importance of an assessment of the pre-flood and flood conditions on their environmental, social, and economic aspects [46]. As hazards for any community are driven by the interactions between the human and the natural 
systems [12,17], ecological flood risk assessment makes vulnerability - resilience relationships more transparent.

\subsection{Interactions between ecological vulnerability and resilience}

Examining ecological vulnerability and resilience, allows detecting the wide spectrum of interactions between multiple stress events and resources across contexts, scale, time and stakeholder involvement. This concern applies to the assessment of any type of hazard $[36,45]$. In an ideal, simplified context, ecological vulnerability and ecological resilience are opposite [17]. Ecological vulnerability refers to stress that might originate from many sources, including non-flood related incidents [46]. While ecological resilience describes the changes of adaptation and coping capacity in multiple regimes across scale and time, vulnerability as defined by all schools of thought is not symmetrical to ecological resilience. The first school of thought considers vulnerability and resilience as two sides of a flipping coin. This school ignores that pre-flood environmental, social and economic conditions modify the outcome (positive or negative) of vulnerability [46]. The second school of thought calculates vulnerability only during flood incidents. Although the third school of thought deals with vulnerability as a dynamic process, the pre-flood interactions between vulnerability and resilience remain vague. Dealing with these drawbacks, a new framework combining the first and third school of thought has been established. In general, ecological vulnerability and resilience are normalized as stress and resources over scale and time. Their interactions within environmental, social, and economic aspects evolve in a non-linear way from pre flood to flood situations. Major points of the new framework are:

- Ecological vulnerability and resilience will be presented in terms of stress and resources. This point is based on the work of Norris et al. [7] and Wilson [1]. Their separation as two sides of the same coin allows simplifying the definitions of vulnerability and resilience. However, one should keep in mind that both vulnerability and resilience can generate positive and/or negative outcomes [39].

- At a specific scale and time, regardless of flood, ecological vulnerability and resilience indices of a measurement unit (e.g. a county) are composites of a wide array of stress events and resources with environmental, social and economic aspects. As mentioned by the third school, stakeholder agreement on indices is crucial to distinguish between vulnerability and resilience. Defining a measurement unit is equally important because this assists in delineating the boundaries between focal, and upper and/or lower systems [42].

- To quantify the flood assessment, stress and resource indicators must be normalized to the same scale, e.g. using a min-max scaling [13]. Environmental, social, and economic indicators contain both quantitative and qualitative aspects. Using the same scale helps quantifying composite stress aspects and resources during pre-flood and flood.

- To understand the momentum of the system from pre-flood to flood, the stress over resources ratio is calculated. Unlike the three schools of thought relying on flood incidents and calculate flood risk based on 'minus' and/or 'plus' between vulnerability and resilience, the ratio allows (i) determining 'how much' to which extent the system will move, and (ii) when and where there are needs providing additional resources to achieve the equilibrium of the system (see Figure 3). For a specific context, time and scale, if stress and resources respectively generate positive and negative outcomes, the stress and/or resources will be amplified. For another context, time and scale the ratio continues to show two sides of the 
same coin. The first school of thought considers only outcomes, and therefore, cannot reflect on dynamic changes of stress and resources and its analyses are not transferrable.

- The stress over resources ratio allows detecting resistant and creative or flexible regimes and thresholds. In a resistant regime, the stress is larger than the resources. In a creativeflexible regime, the opposite applies. The thresholds cover a range of values around 1 depending on the available data and the decisions of the stakeholders.

- The distribution of the ratio in a defined space generates multiple regimes and thresholds, which lack in the first school of thought.

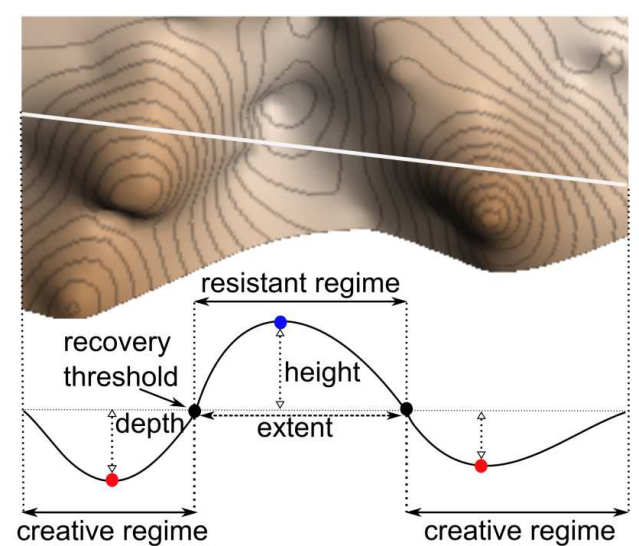

(a)

(b)

Fig 3. The distribution of stress over resources ratios at a specific scale and time. The ratios vary across geographical areas. The equilibrium value between stress and resources is 1 , also called the recovery threshold. Besides the equilibrium is regimes, in which stress is higher or lower than the resources. A regime is creative when the ratios are smaller than 1 (more resources than stress) while it is resistant if the ratios are greater than 1 (more stress than resources). The regimes are characterized by depth, height and extent. The red point is the minimum ratio between stress and resources within a creative regime. The blue point is the maximum height coinciding with the maximum ratio in a resistant regime. The more the height or the depth is, the more energy the system needs to change within the regimes. The extent connects recovery thresholds between regimes. It defines the maximum change a system can take before shifting to another regime. The larger the extent is, the slower the shift can achieve. After Beroya-Eitner

[17], Frommer [2], and Walker et al. [47].

Figure 3 illustrates the dynamic interactions between stress and resources for a specific scale and time frame. Location specific strategies for sustainable development of communities require defining thresholds and regimes of the interactions between stress events and resources [17]. For any specific context, time, and scale, the relationships between stress and resources can be characterized as a state of recovery, creativity, or resistance [2]. The balance between stress and resources defines the recovery capacity of the system. A regime characterizes unique behavior and functions of the observed system influenced by specific hazards [35, 46]. For instance, soils in countries along the Alpine-Carpathian Mountains respond in a variety of ways to floods [48]. If the system has access to abundant resources to deal with stress, it is a creative regime. A regime is resistant when its coping capacity does not allow adapting to adverse events $[17,49,50]$. The extent and the depth or height are important characteristics of a regime. The extent connects recovery thresholds between regimes. It decides the maximum changes of a system before losing its ability to recover $[2,47]$. Under a creative regime, the extent indicates 
the maximum stress to balance with the resources. In a resistant regime, the extent specifies the maximum amount of resources, which allows eliminating the stress. The depth or height represents how difficult or easy to the system changes [47]. Depending on the available data, multiple levels of minima and maxima exist in a defined space.

\subsection{The dynamics of the system before and during floods}

Analyzing the movement of the system between flood and non-flood situations necessitates an adequate information system with data on all the main states of environmental, social, and economic indicators across scale and time. Local applications are best characterized by specific indicators. Every area has its own indicators which cover environmental, social and economic aspects. In this context, Cutter et al. [51] published a list of more than a hundred indicators. The state of the system is described by variables of the system [47]. For instance, an ecological system in a floodplain is characterized by both environmental (e.g. soil moisture, water quality), and socio-economic indicators (e.g. land use and age of the population). To quantify the responses of the system to flood, stakeholders will collect data and decide the state of each indicator under both flood and non-flood situations (section 4). A simplified state of the system might be described by: soil moisture (low, high), water quality (clear, turbid), land use (agriculture, bare land), and age (under 18, over 18). It is essential that stakeholders agree on defining the state [43] which characterizes the system. Once one indicator changes, the whole system changes, e.g. water changes from clear to turbid due to flood [52].

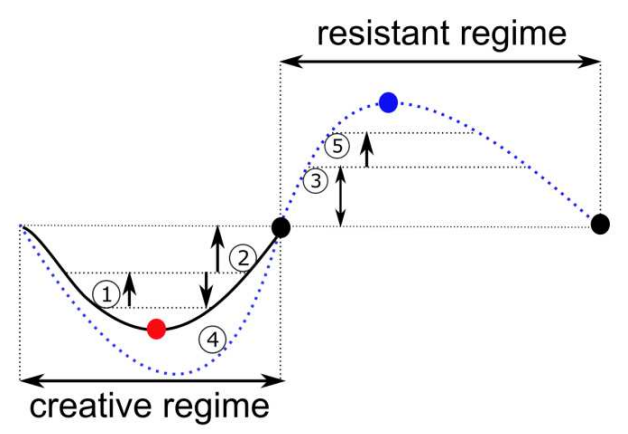

Fig 4. Movements of the system within and between regimes. The arrows indicate moves to particular states of the system. The dotted blue line defines regimes with different characteristics as compared to the solid one (black line).

Studies on flood risk management often quantify vulnerability during the flood. As a consequence, they do not cover the whole range of stress from pre-flood to flood situations and only prepare for part of the upcoming adverse consequences. Suppose that during a stable preflood situation a community is well protected by infrastructure, keeping the risk under control [35] and the economic, social, and environmental context is acceptable. The absence of one of these vulnerability aspects will cause stress on the community even when there is no flood [1]. Under non-flood conditions the system likely moves within the designed regime and there is no need for a regime shift. Without a flood the system might use external resources [8]. In theory it is even possible that the system moves into the creative regime at locations 1 or 2 of Figure 4. However, the gradual shift to another regime is possible if the stress is not addressed in the longterm [46]. Regardless of flood, the socio-economic conditions of the system might gradually erode the capacity of the system. For instance, cities in most developing countries invade agricultural areas and cause shifts. When the system changes from pre-flood to flood, the 
momentum of interactions between stress and resources is more pronounced (Figure 4). Flood will add to the vulnerability, changing the system. In case the policy remains unchanged, the components of the system will differ during pre-flood situations and the flood. If the system exceeds its recovery threshold during the flood driven by external abrupt disturbances, internal gradual changes, or both, a new regime will be the result [46]. Once moving into a new regime, it is expensive returning to the previous one. An example is provided by the change from clearwater to turbid lakes [52]. If the disturbances by the flood exceed the resources mentioned in Figure 4, the system will move from state 2 (creative regime) to state 3 (resistant regime) (Figure 4). It is difficult to reverse the system to its original regime. Instead, if management provides sufficient resources to solve the stress, the system possibly surpasses the threshold of the resistant regime which results in a new creative regime (from state 3 to state 4 in Figure 4). This does not only apply to flood risk management. If stakeholders use resources to unexpectedly prevent system changes [39], their actions might increase the current levels of stress and push the system towards the higher level of resistance (from state 3 to state 5 in Figure 4). For example, the 2015 flood in York city (UK) the River Foss was hitting record heights as a result of extreme precipitation. Once the Foss Barrier, York's major flood defense, was submerged, an electricity cut prevents water discharge. Finally, the Foss Barrier was lifted and the water submerged the entire the city.

It is equally important to consider the influences of upper and lower systems on the shifts of the focal regimes $[43,46,47]$. For example, flood risk management at District level should address the relations between the City and the County [13]. Changes of the system will be more complex because decisions taken at different scales consider different types of resources and stress [1]. This is known as the modifiable areal unit problem (MAUP) [53] in which the aggregation from the focal scale to either larger or finer scales often fades out local details. MEA [54] suggested scale-dependent, scale-independent and non-scalable variables to characterize this problem. Examining the changes between non-flood and flood situations at different scales is subject to further studies.

\section{CONCLUSIONS}

The proposed framework integrates major points of the flipping coin (vulnerability and resilience are normalized as stress and resources, and they are two sides of the same coin) and separation concepts (vulnerability and resilience both can generate positive and/or negative outcomes) to address the dynamic interactions between ecological vulnerability and resilience prior to and during floods. Ecological vulnerability involves a wide array of stress types resulting from human-nature interactions. When these concepts are equivalent, it is easy to explain the momentum of the system using the multi flipping-coin approach. The proposed framework however relies on available data and the participation of the stakeholders.

Even when separating ecological vulnerability from resilience (which allows explaining their dynamic interactions) the proposed framework has explicit limitations:

- The framework is limited in designing accurately the maximum stress and resources. This has to do with the available data in the study areas. Data can assist quantifying the depth and height of creative and resistant regimes.

- The specification of a regime is always temporal because environmental, social and economic processes are dynamic and lead to changes in the state of the system.

- Stakeholders help deciding on stress and resources indicators and their state. 
- Conceptualizing ecological vulnerability will make the exercise complex, as it has to deal with: (i) covering stress during and prior to the floods, and (ii) defining variables and state of the environmental, social, and economic processes both prior and during the flood.

- The framework does not focus on long term effects from prior to post-flood scenarios because determining flooding periods is local specific. However, once the momentum between pre-floods and the actual conditions of the system at risk is established, direct causes and solutions for dealing with the flood are provided. The proposed framework is also applicable for post-flood evaluations. As long as the pre-flood and flood conditions are examined, post-flood can be properly handled. The 2005 flood in New Orleans (US) provides an example.

- The focus should not be on urban areas alone. However, in developing countries, urbanization and population growth affect agricultural land use quite dramatically. Lowincome citizens often attempt to settle in floodplains where drainage systems are, as a rule, outdated. The theory addressed by this paper is applicable for both rural and urban areas. Urban or rural resilience is "in se" not different.

- The framework does not provide solutions for cross-scale measurements.

Further studies should explore more knowledge to improve the framework. Additionally, one should pay attention to selecting variables and cross-scale measurements. Selecting appropriate sets of variables for ecological vulnerability and resilience assessment is a daunting task as there is currently no standard. The issue has two major aspects: One is how many variables are enough? And the other one is about which variables characterize best stress and resources? This second aspect re-addresses the crucial role of the stakeholders in the evolution of the system because some resources can amplify stress. Designing spatial units for cross-scale measurements is equally important. Scaling the system up and down between different policy levels requires advanced GIS and Remote Sensing techniques to address the MAUP.

\section{REFERENCES}

1. Wilson G. A. - Community resilience, globalization, and transitional pathways of decision-making, Geoforum 43 (6) (2012) 1218-1231.

2. Frommer B. - Climate change and the resilient society: utopia or realistic option for German regions? Natural hazards 67 (1) (2013) 99-115.

3. Engle N. L., Bremond A. de, Malone E. L. and Moss R. H. - Towards a resilience indicator framework for making climate-change adaptation decisions, Mitigation and Adaptation Strategies for Global Change 19 (8) (2014) 1295-1312.

4. Menoni S., Modaressi H., Schneiderbauer S., Kienberger S. and Zeil P. - Risk Research: ENSUREing to MOVE ahead - A cooperative paper based on the results of the projects ENSURE and MOVE, European Commission, Luxembourg: Publications Office of the European Union (2013).

5. Adger W. N. - Vulnerability, Global Environmental Change 16 (3) (2006) 268-281.

6. Folke C., Carpenter S., Elmqvist T., Gunderson L., Holling C. S. and Walker B. Resilience and sustainable development: building adaptive capacity in a world of transformations, AMBIO: A journal of the human environment 31 (5) (2002) 437-440. 
7. Norris F. H., Stevens S. P., Pfefferbaum B., Wyche K. F. and Pfefferbaum R. L. Community resilience as a metaphor, theory, set of capacities, and strategy for disaster readiness, American journal of community psychology 41 (1-2) (2008) 127-150.

8. Füssel H. M. - Vulnerability: a generally applicable conceptual framework for climate change research, Global environmental change 17 (2) (2007) 155-167.

9. Smit B. and Wandel J. - Adaptation, adaptive capacity and vulnerability, Global environmental change 16 (3) (2006) 282-292.

10. Turner B. - Vulnerability and resilience: Coalescing or paralleling approaches for sustainability science? Global Environmental Change 20 (4) (2010) 570-576.

11. Yohe G., and Tol R. S. - Indicators for social and economic coping capacity - moving toward a working definition of adaptive capacity, Global Environmental Change 12 (1) (2002).

12. Cutter S. L. - The landscape of disaster resilience indicators in the USA, Natural Hazards 80 (2) (2016) 741-758.

13. Cutter S. L. Ash K. D. and Emrich C. T. - The geographies of community disaster resilience, Global Environmental Change 29 (2014) 65-77.

14. Fekete A., Hufschmidt G. and Kruse S. - Benefits and challenges of resilience and vulnerability for disaster risk management, International journal of disaster risk science $\mathbf{5}$ (1) (2014) 3-20.

15. Keessen A. M., Hamer J. M., Van Rijswick H. F. and Wiering M. - The concept of resilience from a normative perspective: examples from Dutch adaptation strategies, Ecology and Society 18 (2) (2013).

16. Modica M., and Reggiani A. - Spatial economic resilience: overview and perspectives, Networks and Spatial Economics 15 (2) (2015).

17. Beroya-Eitner M. A. - Ecological vulnerability indicators, Ecological Indicators 60 (2016) 329-334.

18. De Moel H., Alphen J. van, and Aerts J. - Flood maps in Europe-methods, availability and use, Natural Hazards and Earth System Science 9 (2) (2009) 289-301.

19. Roberts N., Nadim F. and Kalsnes B. - Quantification of vulnerability to natural hazards, Georisk: Assessment and Management of Risk for Engineered Systems and Geohazards 3 (3) (2009) 164-173.

20. Schanze J. - Flood risk management-a basic framework, in J. Schanze, E. Zeman, \& J. Marsalek (Eds.), Flood risk management: Hazards, vulnerability and mitigation measures (2006) 1-20.

21. Scheuer S., Dagmar H. and Meyer V. - Exploring multicriteria flood vulnerability by integrating economic, social and ecological dimensions of flood risk and coping capacity: from a starting point view towards an end point view of vulnerability, Natural Hazards, $\mathbf{5 8}$ (2) (2011) 731-751.

22. Birkmann J. - Measuring vulnerability to promote disaster-resilient societies: Conceptual frameworks and definitions, in J. Birkmann (Eds.), Measuring vulnerability to natural hazards: Towards disaster resilient societies second edition, United Nations University Press, Tokyo, Japan (2013) 9-54. 
23. UNISDR - 2009 UNISDR terminology on disaster risk reduction, United Nations International Strategy for Disaster Reduction, Geneva, Switzerland. accessed 12 January 2016 [http://www.unisdr.org/we/inform/publications/7817] (2009).

24. Dewan A. M. - Hazards, Risk, and Vulnerability, in A. Dewan (Eds.), Floods in a megacity: geospatial techniques in assessing hazards, risk and vulnerability (2013) 35-74.

25. Bizimana J. P. and Schilling M. - Geo-Information Technology for Infrastructural Flood Risk Analysis in Unplanned Settlements: a case study of informal settlement flood risk in the Nyabugogo flood plain, Kigali City, Rwanda, in P. S. Showalter and Y. Lu (Eds.), Geospatial techniques in urban hazard and disaster analysis, Springer (2010) 99-124.

26. Kaźmierczak A. and Cavan G. - Surface water flooding risk to urban communities: Analysis of vulnerability, hazard and exposure, Landscape and Urban Planning 103 (2) (2011) 185-197.

27. Viveros E.M. and Caloca F.L. - A cybercartographic tool for supporting disaster prevention planning processes and emergency management in Mexico City, in P.S. Showalter and Y. Lu (Eds.), Geospatial techniques in urban hazard and disaster analysis, Springer (2010) 255-271.

28. Pavri F. - Urban Expansion and Sea-Level Rise Related Flood Vulnerability for Mumbai (Bombay), India Using Remotely Sensed Data, in P. S. Showalter and Lu (Eds.), Geospatial techniques in urban hazard and disaster analysis, Springer (2010) 31-49.

29. Bogardi J. and Birkmann J. - Vulnerability Assessment: The First Step Towards Sustainable Risk Reduction, in D. Malzahn \& T. Plapp (Eds.), Disaster and Society From Hazard Assessment to Risk Reduction, Berlin: Lagos Verlag Berlin (2005) 75-82.

30. Cardona O.D. - Environmental Management and Disaster Prevention: Two Related Topics: A Holistic Risk Assessment and Management Approach, in J. Ingleton (Eds.), Natural Disaster Management, London: IDNDR-Tudor Rose (1999) 151-153.

31. Cardona O.D. - Estimación Holística del Riesgo Sísmico Utilizando Sistemas Dinámicos Complejos, Barcelona: Technical University of Catalonia, accessed 12 January 2016, [http://www.desenredando.org/public/varios/2001/ehrisusd/index.html] (2001).

32. Fekete A., Damm M. and Birkmann J. - Scales as a challenge for vulnerability assessment, Natural Hazards 55 (3) (2010) 729-747.

33. Schumann A.H. - Introduction-Hydrological Aspects of Risk Management, in A.H. Schumann (Eds.), Flood Risk Assessment and Management, Springer (2011) 1-10.

34. Holling C. S. - Resilience and stability of ecological systems, Annual review of ecology and systematics 4 (1973) 1-23.

35. Liao K. H. - A Theory on Urban Resilience to Floods - A Basis for Alternative Planning Practices, Ecology and Society 17 (4) (2012) 48.

36. Lange H. D., Sala S., Vighi M., and Faber J. -. Ecological vulnerability in risk assessment - A review and perspectives, Science of the Total Environment 408 (18) (2010) 38713879.

37. Sharifi A. and Yamagata Y. - Major principles and criteria for development of an urban resilience assessment index, Green Energy for Sustainable Development (ICUE), 2014 International Conference and Utility Exhibition on, IEEE (2014). 
38. Jacobs B., Nelson R., Kuruppu N. and Leith P. - An adaptive capacity guide book: Assessing, building and evaluating the capacity of communities to adapt in a changing climate, Southern Slopes Climate Change Adaptation Research Partnership (SCARP), University of Technology Sydney and University of Tasmania, Hobart, Tasmania (2015).

39. Menoni S., Molinari D., Parker D., Ballio F. and Tapsell S. - Assessing multifaceted vulnerability and resilience in order to design risk-mitigation strategies, Natural Hazards 64 (3) (2012) 2057-2082.

40. Adger W. N., Brooks N., Bentham, G., Agnew M., and Eriksen, S. - New indicators of vulnerability and adaptive capacity, Tyndall Centre for Climate Change Research, Norwich (2004).

41. Lam N. S., Reams M., Li K., Li C. and Mata L. P. - Measuring Community Resilience to Coastal Hazards along the Northern Gulf of Mexico, Natural Hazards Review 17 (1) (2016) 1-12.

42. Kienberger S., Lang S. and Zeil P. - Spatial vulnerability units - expert-based spatial modelling of socio-economic vulnerability in the Salzach catchment, Austria, Natural Hazards and Earth System Sciences 9 (3) (2009) 767-778.

43. Miller F., Osbahr H., Boyd E., Thomalla F., Bharwani S., Ziervogel G., Walker B., Birkmann J., Van der Leeuw S., Rockström J., Hinkel J., Downing T., Folke C. and Nelson D. - Resilience and vulnerability: complementary or conflicting concepts? Ecology and Society 15 (3) (2010).

44. Birkmann J. - Regulation and coupling of society and nature in the context of natural hazards, in H. G. Brauch, Ú. O. Spring, C. Mesjasz, J. Grin, P. Kameri-Mbote, B. Chourou, et al. (Eds.), Coping with Global Environmental Change, Disasters and Security: Threats, Challenges, Vulnerabilities and Risks, Springer (2011) 1103-1127.

45. Lucas A. M. J., and Kibler K. M. - Integrated Flood Management in developing countries: balancing flood risk, sustainable livelihoods, and ecosystem services, International Journal of River Basin Management 14 (1) (2016) 19-31.

46. Filatova T., Polhill J.G. and van Ewijk S. - Regime shift in coupled socio-environmental systems: Review of modelling challenges and approaches, Environmental Modelling \& Software 75 (2016) 333-347.

47. Walker B., Holling C.S., Carpenter S.R. and Kinzig A. - Resilience, Adaptability and Transformability in Social-ecological Systems, Ecology and Society 9 (2) (2004) 5-13.

48. Parajka J., Kohnová S., Bálint G., Barbuc M., Borga M., Claps P., Cheval S., Dumitrescu A., Gaume E., Hlavčová K., Merz R., Pfaundler M., Stancalie G., Szolgay J. and Blöschl G. - Seasonal characteristics of flood regimes across the Alpine-Carpathian range, Journal of Hydrology 394 (1-2) (2010) 78-89.

49. IPCC - Climate Change: New Dimensions in Disaster Risk, Exposure, Vulnerability, and Resilience, in C. B. Field, V. Barros, T. F. Stocker, D. Qin, D. J. Dokken, K. L. Ebi, et al. (Eds.), Managing the Risks of Extreme Events and Disasters to Advance Climate Change Adaptation: special report of intergovernmental panel on climate change, Cambridge University Press, Cambridge, UK and New York, NY, USA (2012) 27-64.

50. UNISDR - Living with risk: a global review of disaster reduction initiatives, United Nations, International Strategy for Disaster Reduction, UNISDR, accessed 12 January 2016 [http://www.unisdr.org/we/inform/publications/657] (2004). 
51. Cutter S.L., Boruff B.J. and Shirley W.L. - Social Vulnerability to Environmental Hazards, Social Science Quarterly 84 (2) (2003) 242-261.

52. Mens M.J.P., Klijn F., de Bruijn K.M., van Beek E. - The meaning of the system robustness for flood risk management, Environmental Science \& Policy 14 (8) (2011) 1121-1131.

53. Marceau D. J. and Hay G. J. - Remote sensing contributions to the scale issue, Canadian journal of remote sensing 25 (4) (1999) 357-366.

54. MEA - Ecosystems and human well-being: a framework for assessment, Island Press Washington, DC (2005). 